\title{
Experiences of PCOS diagnosis in a cohort of Polish women from the Pomeranian region: A questionnaire-based cross- sectional study
}

\author{
Edyta Dutkiewicz ${ }^{1}$, Dominik Rachon ${ }^{1 *}$, Helena Teede ${ }^{2,3}$ and Melanie Gibson-Helm ${ }^{2}$ \\ ${ }^{1}$ Department of Clinical and Experimental Endocrinology, Medical University of Gdańsk, Dębinki 7, 80-211 Gdańsk, Poland \\ ${ }^{2}$ Monash Centre for Health Research and Implementation, School of Public Health and Preventive Medicine, Monash University, Clayton, Victoria 3168, Australia \\ ${ }^{3}$ Monash Partners Academic Health Research Translation Centre, Clayton, Victoria 3168, Australia
}

\begin{abstract}
Background: The challenges of living with PCOS may be exacerbated by a long and problematic process of diagnosis or a lack of evidence-based, personally relevant information. Therefore, the aim of our study was to evaluate the time to diagnosis, the number of health professionals seen, and patients' information needs in a cohort of women with PCOS.

Methods: A validated questionnaire was distributed via e-mail to 220 Polish women diagnosed with PCOS.

Results: In total 100 women completed the questionnaire. Among almost $40 \%$ of the respondents the process of diagnosis lasted more than 24 months and $50 \%$ of cases required seeing more than three health care professionals. Almost $65 \%$ of women pointed to the need for information on PCOS in the form of treatment standards and educational materials (16\%). Only $5 \%$ of the respondents reported the need for a web page devoted to PCOS. Women were also asked about the burden of PCOS symptoms. More than $40 \%$ of the respondents highlighted weight gain (42\%) and inability to lose weight (41\%) as the most problematic. Fertility problems, depression, and mood swings as well as hirsutism were noted by $36 \%$, 34\% and 33\% of the respondents, respectively. Skin problems and acne were the least problematic (only for $26 \%$ of the respondents).
\end{abstract}

Conclusions: These results suggest that the process of PCOS diagnosis is prolonged, requires seeing multiple health professionals and is not supported by reliable information and resources on long-term complications and therapeutic options.

\section{Introduction}

Polycystic ovary syndrome (PCOS) in recent years has gained a lot of attention not only due to its high prevalence (8-13\%) [1] and its unfavourable reproductive and metabolic consequences [2], but also due to the negative impact on psychological health [3]. Features of PCOS that may affect psychological health include the chronic nature of the condition, fertility problems, overweight or obesity, hirsutism, and acne [4]. The challenges of living with PCOS may be further exacerbated by a long and problematic process of diagnosis or a lack of evidence-based, personally relevant information [5]. A preliminary study [6] involving a sample of 210 women in Australia diagnosed with PCOS showed that the journey to obtaining a PCOS diagnosis can be lengthy, involve many health professionals and leave considerable unmet information needs. This research was then extended to over 1000 women in North America and Europe generally, with similarly concerning findings [7]. To address these needs, the international evidence-based guideline on PCOS was developed [4]. Alongside the guideline, a broad array of translation resources was developed for women and healthcare providers [8].

However, these previous studies were conducted with Englishspeaking women only; the experiences of non-English speaking women are vastly under-represented in the research literature. We hypothesise that the information needs of non-English speaking women may also be even greater, as most of the evidence-based information about PCOS for women has only been available in English. Thus, together with the authors of these former studies we decided to conduct a similar study among women from the Pomeranian region of Poland. We also sought to establish the gaps that can be addressed by co- designed and translated resources.

Therefore, the main goal of this study was to investigate 'PCOS diagnosis experiences', women's concerns (including about the name of the condition) and their information needs.

\section{Materials and methods}

\section{Study design, setting, and participants}

Patients were recruited by a specialist in internal medicine and endocrinology (D.R.) from two outpatient endocrinological practices based in the Pomeranian region of Poland (one in Gdańsk and other in Gdynia). Eligibility criteria included: age $18-45$ years, a prior medical diagnosis of PCOS according to the AE\&PCOS criteria, which include

${ }^{\star}$ Correspondence to: Dominik Rachon, Head of the Department of Clinical and Experimental Endocrinology, Medical University of Gdańsk, Dębinki 7, Gdańsk, Poland, Tel: +48 604895 009; E-mail: dominik.rachon@gumed.edu.pl

Key words: polycystic ovary syndrome, diagnosis, Poland, health personnel, quality of life, depression, emotions, personal satisfaction

Received: August 07, 2020; Accepted: August 24, 2020; Published: August 27, 2020 
the presence of clinical or biochemical hyperandrogenism and ovarian dysfunction defined as anovulation or oligomenorrhea or/and the presence of polycystic ovary morphology (PCOM) on transvaginal ultrasound (TV USG) [9]. Exclusion criteria included current pregnancy or diagnosis of a psychiatric illness other than depression or anxiety. An e-mail with a link to a web-based questionnaire (created using the SurveyMonkey web site) was sent during the period of December 2018 and January 2019 to 220 women. Participation was voluntary and the completion of the survey was taken as consent. The study was approved by the Bioethics Committee of the Medical University of Gdańsk (permission nr NKBBN/412/2018).

\section{Statistical analyses}

The questionnaire, which was developed with input from women with PCOS and a multidisciplinary advisory group in Australia and piloted by [6] and used in a large sample of women in Europe (7), was adapted and translated into Polish language (by E.D. and D.R.). It included questions on the 'PCOS diagnosis experience', information provided at diagnosis, current concerns about PCOS features, support needs and women's perceptions related to the syndrome's name (Supporting Information Appendix S1). All the calculations were performed using the Microsoft Excel programme for Mac OS. Categorical data are presented as count and proportions and continuous data as mean \pm standard deviation (SD).

\section{Results}

Overall, 105 women responded to the questionnaire (response rate $48 \%$ ), however 5 responses were incomplete leaving 100 responses for evaluation. Mean age of the respondents was $27 \pm 5$ years (min-max: 18 - 42 years) and mean BMI 25.4 (min-max: 15.8 - 45.4). Eighteen per cent of the respondents were overweight (BMI 25-29.9) and $24 \%$ were obese $(\mathrm{BMI}>30)$. Fifty-five per cent had a healthy body weight (BMI 18.5-24.9). Thirty-nine per cent of the respondents reported that the process of obtaining the final PCOS diagnosis lasted more than 24 months. In only $36 \%$ of the cases, it lasted less than 6 months. More than one-third (34\%) of the respondents also reported that before obtaining the final PCOS diagnosis they had visited three or four health care professionals and $16 \%$ had visited more than five. Overall, only $50 \%$ of PCOS cases were diagnosed after seeing one or two specialists. Only $46 \%$ of the respondents were satisfied with the diagnosis experience and only $42 \%$ were satisfied with the information obtained on the possible therapeutic options such as lifestyle change (diet and physical activity) and pharmacotherapy. Only one-fourth (26\%) of the respondents were satisfied with the information related to the long-term consequences of PCOS and only $29 \%$ were satisfied with the emotional support provided by the diagnosing physician. The characteristics of the "PCOS diagnosis experience" in our cohort are presented in table 1.

When asked about how women with PCOS could be better supported, almost $65 \%$ of women pointed to the need for more information on PCOS and its consequences in the form of treatment standards and educational materials (16\%). Only $5 \%$ of the respondents reported the need for a web page devoted to PCOS.

Women were also asked about the burden of PCOS symptoms. More than $40 \%$ of the respondents highlighted weight gain (42\%) and difficulty losing weight (41\%) as the most problematic symptoms. Fertility problems, depression, and mood swings as well as hirsutism were noted by $36 \%, 34 \%$ and $33 \%$ of the respondents, respectively. Skin problems and acne were the least problematic (only for $26 \%$ of the respondents) (Figure 1).

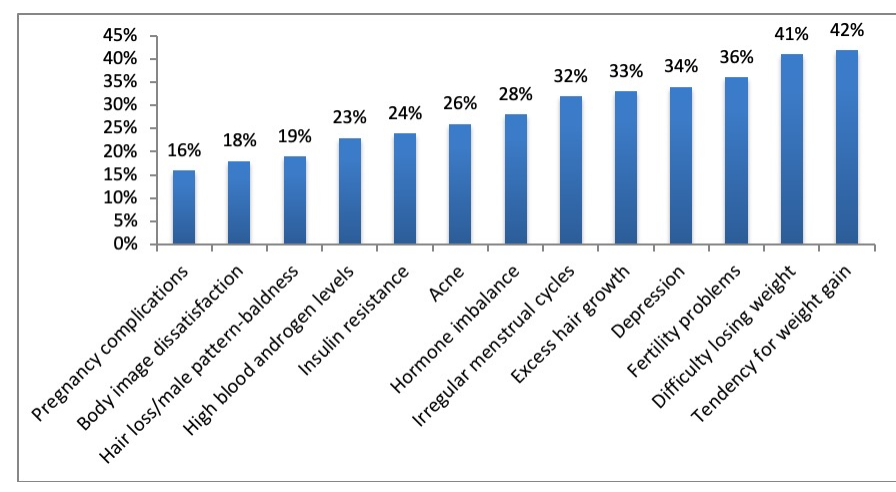

Figure 1. The most problematic clinical features of PCOS in the study cohort $(n=100)$

Table 1. "PCOS diagnosis experience" among women from the Pomeranian region of Poland $(\mathrm{n}=100)$

\begin{tabular}{|c|c|}
\hline & $\mathrm{N}=100$ \\
\hline $\begin{array}{l}\text { Time until diagnosis } \\
\text { Within } 6 \text { months } \\
\text { Between } 6 \text { and } 12 \text { months } \\
\text { Between } 12 \text { and } 24 \text { months } \\
\text { More than } 24 \text { months }\end{array}$ & $\begin{array}{l}36 \% \\
14 \% \\
11 \% \\
39 \%\end{array}$ \\
\hline $\begin{array}{l}\text { Number of health professionals seen before diagnosis } \\
1-2 \\
3-4 \\
\geq 5\end{array}$ & $\begin{array}{l}44 \% \\
34 \% \\
16 \%\end{array}$ \\
\hline $\begin{array}{l}\text { Satisfaction with manner of diagnosis } \\
\text { Dissatisfied } \\
\text { Neither satisfied nor dissatisfied } \\
\text { Satisfied }\end{array}$ & $\begin{array}{l}38 \% \\
16 \% \\
46 \%\end{array}$ \\
\hline $\begin{array}{l}\text { Satisfaction with information given about medical therapy } \\
\text { Dissatisfied or indifferent } \\
\text { Satisfied }\end{array}$ & $\begin{array}{l}58 \% \\
42 \%\end{array}$ \\
\hline $\begin{array}{l}\text { Satisfaction with information given about lifestyle management } \\
\text { Dissatisfied or indifferent } \\
\text { Satisfied }\end{array}$ & $\begin{array}{l}58 \% \\
42 \%\end{array}$ \\
\hline $\begin{array}{l}\text { Satisfaction with information about long-term complication } \\
\text { Dissatisfied or indifferent } \\
\text { Satisfied }\end{array}$ & $\begin{array}{l}74 \% \\
26 \%\end{array}$ \\
\hline $\begin{array}{l}\text { Satisfaction with emotional support and counselling after } \\
\text { diagnosis }\end{array}$ & \\
\hline $\begin{array}{l}\text { Dissatisfied or indifferent } \\
\text { Satisfied }\end{array}$ & $\begin{array}{l}71 \% \\
29 \%\end{array}$ \\
\hline $\begin{array}{l}\text { Satisfaction with information given about lifestyle management } \\
\text { Dissatisfied or indifferent } \\
\text { Satisfied }\end{array}$ & $\begin{array}{l}58 \% \\
42 \%\end{array}$ \\
\hline $\begin{array}{l}\text { Satisfaction with information about long-term complication } \\
\text { Dissatisfied or indifferent } \\
\text { Satisfied }\end{array}$ & $\begin{array}{l}74 \% \\
26 \%\end{array}$ \\
\hline $\begin{array}{l}\text { Satisfaction with emotional support and counselling after } \\
\text { diagnosis }\end{array}$ & \\
\hline $\begin{array}{l}\text { Dissatisfied or indifferent } \\
\text { Satisfied }\end{array}$ & $\begin{array}{l}71 \% \\
29 \%\end{array}$ \\
\hline
\end{tabular}

\section{Discussion and conclusion}

This study evaluated PCOS diagnosis experiences in a cohort of Polish women from the Pomeranian region. In a study conducted by Deeks et al. [10], a prolonged process of PCOS diagnosis was associated 
with poor psychological functioning and depression. This has the potential to negatively impact the motivation to life-style change, which is an important aspect of non-pharmacological treatment of women with this syndrome [4]. Both our and the data from Australia, confirm the need to provide women with PCOS with information on current treatment standards and educational materials at the time of diagnosis [11]. To our knowledge this is the first study conducted among Polish women, which evaluated diagnosis experiences in women with PCOS and contributes important knowledge about the needs of non-English speaking women.

Our results are consistent with previous research suggesting that a considerable number of women with PCOS experience delays in obtaining a diagnosis and visit multiple healthcare providers of different specialities [7]. Similar to our cohort, approximately onethird of women with PCOS in North America and Europe reported the time to diagnosis to be more than 24 months and more than $10 \%$ of women reported seeing more than 5 health professionals before the final diagnosis was made. Nevertheless, the proportion of women satisfied with their diagnosis experience or with the information received is higher in our study than in previous research [7]. A possible explanation for this is that women were recruited from two outpatient endocrinological practices by the same specialist (D.R.) for this study, whereas the previous international study recruited women from the community. Even so, considerable unmet need is still indicated as less than half the women in this study were satisfied with their diagnosis experience, and satisfaction with information was as low as $26 \%$. Specifically, we hypothesise that these findings indicate a need for improved resources for healthcare providers in order to accelerate the diagnosis of PCOS. Also, in our study more than $60 \%$ of the respondents reported the need for more information on the current treatment recommendations in the form of educational materials (leaflets $15 \%$ ) but surprisingly only $5 \%$ wanted a specific website. This contrasts with data from other studies, which report that women with PCOS obtain a great deal of their information from the internet [11]. Nevertheless, women recognise and can be overwhelmed by the varying quality of information available on the internet [12-15]. Although there is freely available, reliable and evidence based online information prepared by professional Australian, North American and European societies, a recent assessment found that some such information may only be appropriate for women with high levels of English and/ or health literacy [16]. The authors concluded there is a lack of easyto-read evidence-based information online about PCOS for women. Online information specifically about lifestyle management for PCOS has also found to be limited, and of suboptimal accuracy, specificity, and applicability $[16,17]$. We hypothesise that women in our study may anticipate that web-based information may not be accessible enough to meet their needs. In this context, a translation and dissemination program accompanying the international evidence-based guidelines co-designed an extensive range of resources with and for women and health professionals including the "AskPCOS" mobile application and the PCOS Question Prompt List $[8,18,19]$. These resources are now used in over 170 countries and efforts are underway to make them available in languages other than English. Availability of such material in a wide range or languages and formats could accelerate the diagnosis and treatment of women with this syndrome, improve quality of life, and support engagement with lifestyle management $[4,20,21]$.

Our questionnaire also asked about the emotional support given by the health care providers during the process of diagnosis. Our results showed that only one third of the respondents were satisfied with this kind of support at the time of the PCOS diagnosis, although this is considerably greater than previous reports ( $29 \%$ vs. $3 \%, \mathrm{p}<0.001)$ [7]. Previous studies reported that a perceived lack of empathy from PCOS healthcare providers can lead to a lack of trust in the information, treatment or recommendations subsequently provided [13,14,22,23]. There is some evidence that support groups can meet some of the socio-emotional needs of women [22,23]. Another reason not to underestimate the importance of support for emotional wellbeing is that women with PCOS are at an increased risk of experiencing anxiety and depression. For all these reasons, assessment of emotional wellbeing and provision of appropriate referral or treatment is recommended.

The survey also evaluated the burden of PCOS symptoms [4] and the findings provide guidance for healthcare providers about topics to discuss with their patients. The respondents were asked to point out the four most bothersome symptoms related to the PCOS. Although only one quarter of our respondents were obese (BMI $>30$ ), $40 \%$ of them noted obesity and weight gain as of great concern, indicating that women want to discuss weight gain prevention strategies with their healthcare providers. Data from other studies show that obesity and weight loss problems are a strong negative correlate of quality of life $[21,24,25]$. These results also align with the international Guideline recommendations and underline the need for comprehensive life-style change counselling by health care professionals in this patient's setting [4]. One third of the respondents pointed to fertility problems, lowered mood or depression, and hirsutism as the most bothersome symptoms. Previous research has also identified infertility as an important concern for women [7] and is one the most well recognised features of the condition. Depression was also nominated as a key concern and past research has identified it as a topic that women find difficult to talk to healthcare providers about [18]. PCOS is also characterised by clinical signs of hyperandrogenism such as hirsutism, acne and androgenic alopecia [26] and approximately one quarter to one third of surveyed women identified them as key concerns. Data from several studies show that these symptoms also have a negative impact on mood and quality of life [21]. In a meta-analysis conducted by [27] hirsutism and menstrual disturbances were also the strongest correlates of low quality of life in women with PCOS. Information is available to support both women and their health professionals in these areas (https://www. monash.edu/medicine/sphpm $/ \mathrm{mchri} / \mathrm{pcos} /$ resources) but detailed information for women from non-English speaking countries may still be lacking. Limitations of our study include potential selection bias as all respondents were from two outpatient endocrinological practices based in the Pomeranian region of Poland, and therefore might not represent the general Polish population of women with PCOS. Despite this limitation, to our knowledge, this is a first study to evaluate PCOS diagnosis experiences among Polish women.

In conclusion, the results of our study confirm that the process of PCOS diagnosis is prolonged, involves several different specialists and involves limited reliable information provision on long term complications and therapeutic options. This points to the necessity to translate and disseminate the already available evidence-based resources on PCOS in non-English speaking countries.

\section{Funding information}

This study was financed from the funds of the Polish National Centre for Science (grant number 2014/15/B/NZ7/00999). HT and MGH are Australian National Health and Medical Research Council Fellows. 


\section{References}

1. Bozdag G, Mumusoglu S, Zengin D, Karabulut E, Yildiz BO (2016) The prevalence and phenotypic features of polycystic ovary syndrome: a systematic review and metaanalysis. Hum Reprod 31: 2841-2855. [Crossref]

2. Kakoly NS, Earnest A, Teede HJ, Moran LJ, Joham AE (2019) The Impact of Obesity on the Incidence of Type 2 Diabetes Among Women With Polycystic Ovary Syndrome. Diabetes Care 42: 560-567. [Crossref]

3. Cooney LG, Lee I, Sammel MD, Dokras A (2017) High prevalence of moderate and severe depressive and anxiety symptoms in polycystic ovary syndrome: a systematic review and meta-analysis. Hum Reprod 32: 1075-1091. [Crossref]

4. Teede HJ, Misso ML, Costello MF, Dokras A, Laven J, et al. (2018) Recommendations from the international evidence-based guideline for the assessment and management of polycystic ovary syndrome. Hum Reprod 33: 1602-1618. [Crossref]

5. Gibson-Helm M, Tassone EC, Teede HJ, Dokras A, Garad R (2018) The Needs of Women and Healthcare Providers regarding Polycystic Ovary Syndrome Information, Resources, and Education: A Systematic Search and Narrative Review. Semin Reprod Med 36: 35-41. [Crossref]

6. Gibson-Helm ME, Lucas IM, Boyle JA, Teede HJ (2014) Women's experiences of polycystic ovary syndrome diagnosis. Fam Pract 31: 545-549. [Crossref]

7. Gibson-Helm M, Teede H, Dunaif A, Dokras A (2017) Delayed Diagnosis and a Lack of Information Associated With Dissatisfaction in Women With Polycystic Ovary Syndrome. J Clin Endocrinol Metab 102: 604-612.

8. Teede HJ, Misso ML, Boyle JA, Garad RM, McAllister V, et al. (2009) Translation and implementation of the Australian-led PCOS guideline: clinical summary and translation resources from the International Evidence-based Guideline for the Assessment and Management of Polycystic Ovary Syndrome. Med J Aust 209: S3-S8. [Crossref]

9. Azziz R, Carmina E, Dewailly D, Diamanti-Kandarakis E, Escobar-Morreale HF, et al. (2006) Positions statement: criteria for defining polycystic ovary syndrome as a predominantly hyperandrogenic syndrome: an Androgen Excess Society guideline. $J$ Clin Endocrinol Metab 91: 4237-4245. [Crossref]

10. Deeks AA, Gibson-Helm ME, Paul E, Teede HJ (2011) Is having polycystic ovary syndrome a predictor of poor psychological function including anxiety and depression? Hum Reprod 26: 1399-1407. [Crossref]

11. Avery JC, Braunack-Mayer AJ (2007) The information needs of women diagnosed with Polycystic Ovarian Syndrome--implications for treatment and health outcomes. BMC Womens Health 7: 9.

12. Snyder BS (2006) The lived experience of women diagnosed with polycystic ovary syndrome. J Obstet Gynecol Neonatal Nurs 35: 385-392. [Crossref]

13. Tomlinson J, Pinkney J, Adams L, Stenhouse E, Bendall A, et al. (2017) The diagnosis and lived experience of polycystic ovary syndrome: A qualitative study. $J$ Adv Nurs 73: 2318-2326. [Crossref]
14. Crete J, Adamshick P (2011) Managing polycystic ovary syndrome: what our patients are telling us. J Holist Nurs 29: 256-266.

15. Boyle J, Hollands G, Beck S, Hampel G, Wapau H, et al. (2017) Process evaluation of a pilot evidence-based Polycystic Ovary Syndrome clinic in the Torres Strait. Aust J Rural Health 25: 175-181.

16. Chiu WL, Kuczynska-Burggraf M, Gibson-Helm M, Teede HJ, Vincent A, et al. (2008) What Can You Find about Polycystic Ovary Syndrome (PCOS) Online? Assessing Online Information on PCOS: Quality, Content, and User-Friendliness. Semin Reprod Med 36: 50-58. [Crossref]

17. Htet T, Cassar S, Boyle JA, Kuczynska-Burggraf M, Gibson-Helm M, Chiu WL, et al (2018) Informing Translation: The Accuracy of Information on Websites for Lifestyle Management of Polycystic Ovary Syndrome. Semin Reprod Med 36: 80-85.

18. Khan NN, Vincent A, Boyle JA, Burggraf M, Pillay M, et al. (2018) Development of a question prompt list for women with polycystic ovary syndrome. Fertil Steril 110 514-522.

19. Boyle JA, Xu R, Gilbert E, Kuczynska-Burggraf M, Tan B, et al. (2018) Ask PCOS Identifying Need to Inform Evidence-Based App Development for Polycystic Ovary Syndrome. Semin Reprod Med 36: 59-65. [Crossref]

20. Colwell K, Lujan ME, Lawson KL, Pierson RA, Chizen DR (2010) Women's perceptions of polycystic ovary syndrome following participation in a clinical research study: implications for knowledge, feelings, and daily health practices. $J$ Obstet Gynaecol Can 32: 453-459.

21. Ching HL, Burke V, Stuckey BG (2007) Quality of life and psychological morbidity in women with polycystic ovary syndrome: body mass index, age and the provision of patient information are significant modifiers. Clin Endocrinol (Oxf) 66: 373-379. [Crossref]

22. Holbrey S, Coulson NS (2013) A qualitative investigation of the impact of peer to peer online support for women living with polycystic ovary syndrome. BMC Womens Health 13: 51 .

23. Percy CA, Gibbs T, Potter L, Boardman S (2009) Nurse-led peer support group experiences of women with polycystic ovary syndrome. $J$ Adv Nurs 65: 2046-2055.

24. Hahn S, Janssen OE, Tan S, Pleger K, Mann K, et al. (2005) Clinical and psychological correlates of quality-of-life in polycystic ovary syndrome. Eur J Endocrinol 153: 853860. [Crossref]

25. Trent M, Austin SB, Rich M, Gordon CM (2005) Overweight status of adolescent girls with polycystic ovary syndrome: body mass index as mediator of quality of life. Ambul Pediatr 5: 107-111.

26. Rachon D (2012) Differential diagnosis of hyperandrogenism in women with polycystic ovary syndrome. Exp Clin Endocrinol Diabetes 120: 205-259. [Crossref]

27. Bazarganipour F, Taghavi SA, Montazeri A, Ahmadi F, Chaman R, et al. (2015) The impact of polycystic ovary syndrome on the health-related quality of life: A systematic review and meta-analysis. Iran J Reprod Med 13: 61-70. [Crossref]

Copyright: (C2020 Dutkiewicz E. This is an open-access article distributed under the terms of the Creative Commons Attribution License, which permits unrestricted use, distribution, and reproduction in any medium, provided the original author and source are credited. 